\title{
Schiff Base Ligand Coated Gold Nanoparticles for the Chemical Sensing of Fe(III) Ions
}

\author{
Abiola Azeez Jimoh, ${ }^{1}$ Aasif Helal, ${ }^{1}$ M. Nasiruzzaman Shaikh, ${ }^{1}$ Md. Abdul Aziz, ${ }^{1}$ \\ Zain H. Yamani, ${ }^{1}$ Amir Al-Ahmed, ${ }^{2}$ and Jong-Pil Kim ${ }^{3}$ \\ ${ }^{1}$ Center of Research Excellence in Nanotechnology (CENT), King Fahd University of Petroleum and Minerals (KFUPM), \\ Dhahran 31261, Saudi Arabia \\ ${ }^{2}$ Center of Research Excellence in Renewable Energy, King Fahd University of Petroleum and Minerals (KFUPM), \\ Dhahran 31261, Saudi Arabia \\ ${ }^{3}$ Surface Properties Research Team, Korea Basic Science Institute, Busan Center, Busan 609-735, Republic of Korea
}

Correspondence should be addressed to M. Nasiruzzaman Shaikh; mnshaikh@kfupm.edu.sa

Received 13 May 2015; Accepted 13 July 2015

Academic Editor: Subrata Kundu

Copyright (C) 2015 Abiola Azeez Jimoh et al. This is an open access article distributed under the Creative Commons Attribution License, which permits unrestricted use, distribution, and reproduction in any medium, provided the original work is properly cited.

\begin{abstract}
New Schiff base-coated gold nanoparticles (AuNPs) of type AuNP@L (where L: thiolated Schiff base ligand) have been synthesized and characterized using various spectroscopic techniques. The AuNPs and AuNP@L were imaged by transmission electron microscopy (TEM) and were confirmed to be well-dispersed, uniformly distributed, spherical nanoparticles with an average diameter of 8-10 $\mathrm{nm}$. Their potential applications for chemosensing were investigated in UV-Vis and fluorescence spectroscopic studies. The AuNP@L exhibited selectivity for $\mathrm{Fe}^{3+}$ in an ethanol/water mixture (ratio $9: 1 \mathrm{v} / \mathrm{v}$ ). The absorption and emission spectral studies revealed a 1:1 binding mode for $\mathrm{Fe}^{3+}$, with binding constants of $8.5 \times 10^{5}$ and $2.9 \times 10^{5} \mathrm{M}^{-1}$, respectively.
\end{abstract}

\section{Introduction}

In recent years, gold nanoparticles (AuNPs) have attracted substantial attention for their extensive application in drug delivery $[1,2]$, magnetic resonance imaging (MRI) [3, 4], $\mathrm{X}$-ray computed tomography (X-ray CT) [5], catalysis [6], biosensing $[7,8]$, and so forth because their size, shape, and surface functionalization are easily controlled through the ligands and corresponding metal complexes. One of the typical applications of AuNPs in current research is the colorimetric detection of metal ions in the environment as well as in physiological systems because they possess excellent optical properties, such as high extinction coefficients and distance-dependent plasmonic absorption $[9,10]$. However, the challenge moving forward is to prevent aggregation of the nanoparticles in high-ionic-strength solutions because aggregation restricts the broad and practical application of AuNPs in the detection of ionic species [11, 12].

Furthermore, the detection of $\mathrm{Fe}(\mathrm{III})$ at trace levels is relevant because iron, with its chemical versatility, is essential for the proper functioning of numerous organisms in the entire spectrum of the biological system [13]. In the human body, iron is one of the most essential trace elements; deficiency of ferric ion (Fe(III)) in the body causes anemia, hemochromatosis, liver damage, diabetes, Parkinson's disease, and cancer [14-16]. Ferric ions also play critical roles in the growth and development of living cells and catalyze numerous biochemical processes [17]. However, the physiological abundance of $\mathrm{Fe}(\mathrm{III})$ causes imbalance, triggering the failure of multiple organs, such as the heart, pancreas, and liver $[18,19]$. In this regard, the judicious selection and proper design of an adequate receptor are vital. Numerous studies on the development of Schiff base chemosensors for the detection of $\mathrm{Hg}(\mathrm{II}), \mathrm{Zn}(\mathrm{II}), \mathrm{Al}(\mathrm{III})$, and other ions have recently been reported in the literature [20-22]. However, the availability of chemosensors for Fe(III) that have a high detection threshold is rather limited and the amount of material required to detect a signal is high.

Conventional detection of $\mathrm{Fe}^{3+}$ relies on several standard analytical techniques such as inductively coupled plasma 
atomic emission spectrometry (ICP-AES) [23], inductively coupled plasma mass spectrometry (ICPMS) [24, 25], atomic absorption spectrometry (AAS) [26], and voltammetry [27]. However, these methods are expensive, bulky, and time consuming because they require tedious pretreatment procedures for sample preparation. However, fluorescence microscopy, which is based on optical fluorescence, is a simple, easy, inexpensive, and highly selective tool for studying the localization, trafficking, and expression levels of biomolecules and metal ions within living cells [28]. Most $\mathrm{Fe}^{3+}$ sensing methods are based on an organic chemosensor that either undergoes fluorescence quenching because of the paramagnetic nature of ferric ion [29] or undergoes a "turn on" mechanism [30].

In the search of a new chemosensor with high sensitivity and a very low detection limit for Fe(III), the combination of nanotechnology and a metal binding unit became an obvious choice. AuNPs, which exhibit good optical properties as signaling units as well as the ability to carry higher payloads on their surface and ligands with strong coordinating elements, have enabled the development of a suite of highly efficient chemosensors. However, the literature contains few reports of their application. For example, Zhang et al. reported excellent dispersion AuNPs for detecting sugars by the hypsochromic surface plasmon resonance (SPR) shift [31]. Bai et al. also reported 4-piperazinyl-1,8naphthalimide functionalized AuNPs for Fe(III) recognition, and their results were highly encouraging [32].

Here, we report the synthesis of a thiolated Schiff base ligand by the reaction of salicylaldehyde and 4aminothiophenol, followed by its subsequent anchoring onto the surface of AuNPs through replacing citrate as a stabilizing agent. The results of the characterization of the ligand and the resulting surface-functionalized AuNP@L are described. The efficiency of the AuNP@L as a chemosensor is also reported here on the basis of the results of fluorescence and UV-Vis studies.

\section{Experimental}

2.1. General Remarks. All of the chemicals and solvents were purchased from Sigma-Aldrich. The ${ }^{1} \mathrm{H}$ and ${ }^{13} \mathrm{C}$ NMR spectra and chemical shifts were recorded in deuterated chloroform $\left(\mathrm{CDCl}_{3}\right)$ on a JEOL $500 \mathrm{MHz}$ spectrometer. FT-IR spectra were collected on Nicolet (Thermo Scientific) spectrometer using iTR as a sample holder in the wavenumber range from 600 to $4000 \mathrm{~cm}^{-1}$. Absorption spectra were collected at room temperature in the $4000-400 \mathrm{~cm}^{-1}$ range using a JASCO-670 spectrophotometer, and emission spectra were acquired on a Fluorolog (Horiba) system. Diffraction data were collected on a Rigaku model MiniFlex II diffractometer equipped with a $\mathrm{Cu}-\mathrm{K} \alpha$ radiations source. The data were acquired over the $2 \theta$ range between 25 and $110^{\circ}$. The surface morphology of the NPs was discerned by field-emission scanning electron microscopy (FESEM) on a microscope (LYRA 3 Dual Beam, Tescan) operated at $30 \mathrm{kV}$. FESEM samples were prepared from either a suspension or a dry powder. The energydispersive X-ray spectra for the chemical and elemental analyses of NPs were also collected using an X-Max detector by Oxford, Inc. TEM was performed on a Philips CM200 operated at $200 \mathrm{kV}$; for the sample preparation, one drop of the aqueous AuNP@L solution was spread onto a 200-mesh copper carbon grid and allowed to dry at room temperature.

2.2. Synthesis of Schiff Base Ligand. The thiolated bidentate Schiff base ligand was prepared (Scheme 1) according to a procedure reported in the literature $[33,34]$. To an ethanolic solution of salicylaldehyde, an equimolar amount of 4aminothiophenol was added, and the mixture was refluxed at $90^{\circ} \mathrm{C}$ for $5 \mathrm{~h}$. The yellow precipitate was filtered, purified by recrystallization from methanol, and finally dried under vacuum to obtain a $91 \%$ yield.

2.3. Synthesis of AuNP@L. AuNPs coated with citrate (AuNP@Cit) were prepared using the citrate (Cit) reduction method in deionized water (Scheme 2). $\mathrm{HAuCl}_{4} \cdot 3 \mathrm{H}_{2} \mathrm{O}$ $(0.33 \mathrm{~g}, 1 \mathrm{mmol})$ in $500 \mathrm{~mL}$ of water was refluxed in a $1 \mathrm{~L}$ round-bottom flask equipped with a condenser. The mixture was stirred vigorously under argon for $30 \mathrm{~min}$. Trisodium citrate $(10 \mathrm{~mL}, 1.14 \mathrm{~g}, 3.88 \mathrm{mmol})$ solution was rapidly added, which resulted in a color change from yellow to purple. After the mixture was boiled for another $10 \mathrm{~min}$, the heating mantle was removed and the mixture was allowed to cool at room temperature.AuNP@L was prepared as follows. To the freshly prepared AuNP@Cit (50 mL), Schiff base ligand (5 mg in $0.5 \mathrm{~mL}$ methanol) was added in one portion and stirred for $5 \mathrm{~h}$ at room temperature. The AuNP@L precipitated upon the addition of an equal amount of acetone. The nanoparticles were collected by centrifugation and washed successively with water and acetone to remove the unreacted ligands.

\section{Results and Discussion}

3.1. Synthesis and Characterization. The 2-[(4-mercaptophenyl)imino methyl] phenol Schiff base (L) was prepared by the reaction between salicylaldehyde and 4-aminothiophenol in ethanol (1:1 mole/mole) under reflux conditions for $5 \mathrm{~h}$ (Scheme 1). The resulting yellow solid was recrystallized from methanol in $94 \%$ yield. The formation of the imino ligand was confirmed by ${ }^{1} \mathrm{H}$ and ${ }^{13} \mathrm{C} \mathrm{NMR}$, which showed a characteristic olefinic proton shift at $\delta 8.9 \mathrm{ppm}$, supported by the olefinic carbon shift at $\delta 160.2 \mathrm{ppm}$ (see supporting information in Supplementary Material available online at http://dx.doi.org/10.1155/2015/101694). The FT-IR spectra of the imino ligand showed peaks at $1614 \mathrm{~cm}^{-1}$ and $3448 \mathrm{~cm}^{-1}$, corresponding to the vibration modes of the $\mathrm{C}=\mathrm{N}$ and $\mathrm{OH}$ groups, respectively. As a result of coordination of the bare ligand with the $\mathrm{Fe}^{3+}$, the $\mathrm{C}=\mathrm{N}$ band shifted to a lower wavenumber $\left(1609 \mathrm{~cm}^{-1}\right)$, indicating the formation of a metal complex. A similar trend was observed for the phenolic group upon participation in coordination with the metal center. The surface of the AuNP@Cit nanoparticles was functionalized via the one-step addition of the ligand in a minimum amount of methanol solution (Scheme 2). Optimization of the Au-toligand molar ratio was critical for the preparation of AuNP@L because excess ligand resulted in aggregation and precipitation. The formation of the AuNP@Cit and AuNP@L was confirmed by spectroscopic techniques. For instance, in the case 


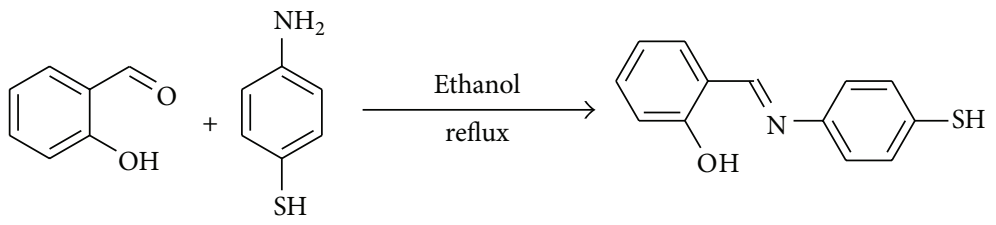

SCHEME 1

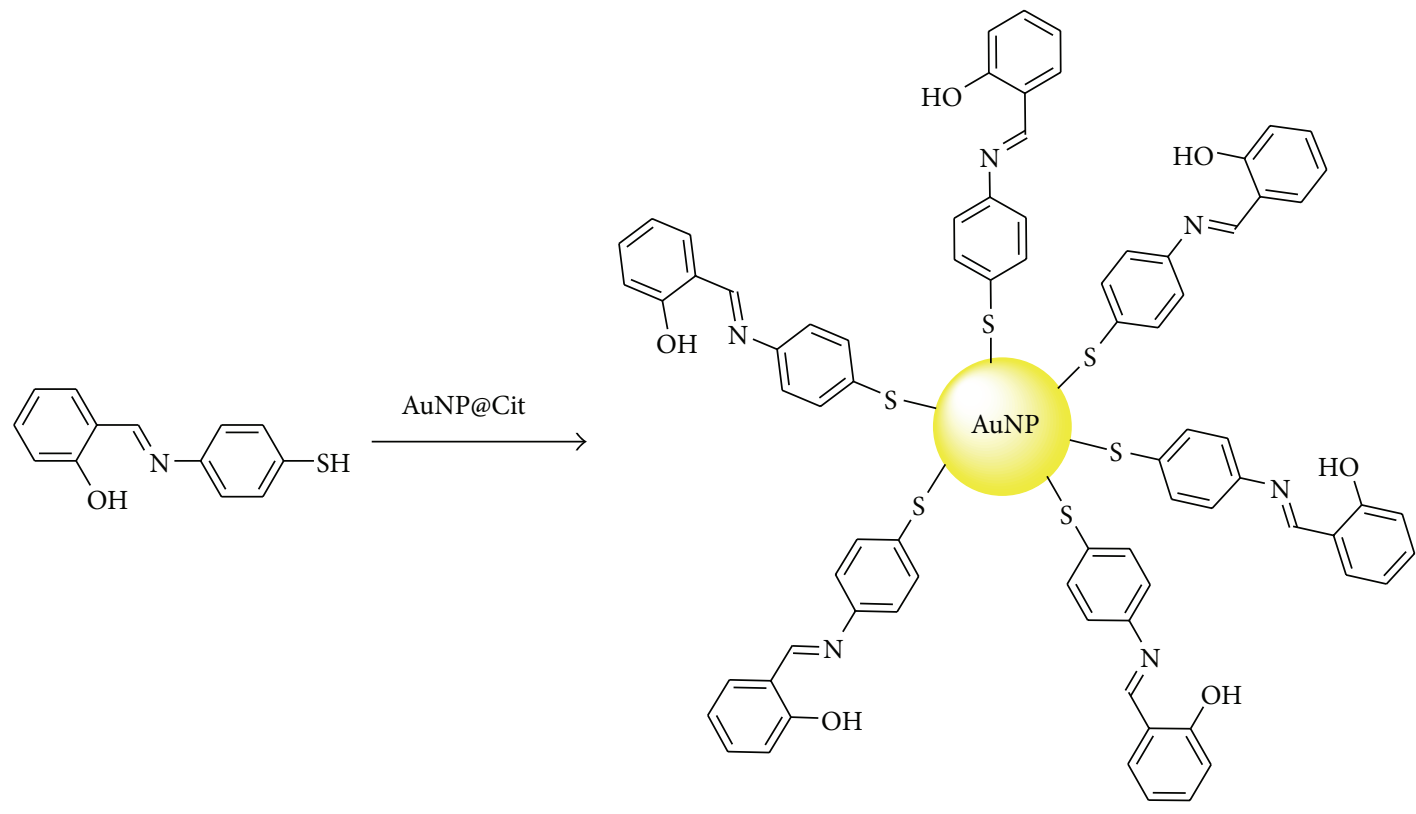

SCHEME 2

of the citrate-coated nanoparticles, visible absorption spectra showed a shift of the absorption band $\left(\lambda_{\max }\right)$ from $525 \mathrm{~nm}$ to $530 \mathrm{~nm}$ for the ligand-modified moieties. This observed shift was attributed to the surface plasmon vibration in the ligandmodified particles. The binding of the thiolated-imino ligand to the Au surface was further confirmed by the disappearance of - $\mathrm{SH}$ stretches in the FT-IR spectrum, indicating Au-S bond formation [35]. The TEM image (Figure 1) shows uniformly distributed spherical particles with an average diameter of $8-$ $10 \mathrm{~nm}$. The peaks at $2 \theta=38.2,44.4,64.5,77.5$, and $81.7^{\circ}$ in the XRD pattern correspond to the (111), (200), (220), (311), and (222) planes in the AuNPs and are identical to those reported in the literature (JCPDS card number: 00-004-0784) [36]. The uniform anchoring of ligands onto the surface of nanoparticles is demonstrated by the energy-dispersive $\mathrm{X}$ ray spectroscopy (EDX) element mapping images in Figures 2(a) and 2(b). Thiols were uniformly anchored onto the Au surface. The structural composition was demonstrated by EDX (Figure 2(c)); carbon, nitrogen, and sulfur were observed to be present on the AuNP surface. A high loading of Schiff base ligand was confirmed from thermogravimetric analysis (TGA), which showed $21.5 \%$ weight loss in the temperature range from 0 to $800^{\circ} \mathrm{C}$ (ramp rate: $10^{\circ} \mathrm{C} / \mathrm{min}$ ), corresponding to the decomposition of the organic ligand.
3.2. UV-Vis Absorption Studies. Preliminary results of the UV-Vis absorption and fluorescent emission studies revealed that the AuNP@L exhibited selectivity toward ferric ions $(10 \mu \mathrm{M})$ in a 9:1 ethanol/water system. As evident in Figure 3, in the absence of ligand, the peak at $525 \mathrm{~nm}$ corresponds to the SPR of AuNPs. Upon attachment of the ligand, this peak red-shifted to $530 \mathrm{~nm}$. Moreover, an additional absorption band appeared at $350 \mathrm{~nm}$; this band was attributed to the $\pi-\pi^{*}$ transition, which is likely favored by the planar orientation enforced by the intramolecular hydrogen bonding in AuNP@L [37]. The addition of $\mathrm{Fe}^{3+}$ causes the plasmonic absorption peak to shift again from 530 to $559 \mathrm{~nm}$.

Interestingly, the presence of other metal ions did not influence the UV-Vis signature, indicating that no aggregation occurred, similar to the observed behavior of ferric ions. However, upon further ingress of ferric ions in the solution containing AuNP@L, the absorption band at $350 \mathrm{~nm}$ was gradually but systematically quenched, whereas that at $530 \mathrm{~nm}$ was synchronously shifted to $559 \mathrm{~nm}$, as shown in Figure 4 . The 530 to $559 \mathrm{~nm}$ shift in the plasmonic absorption band with a gradual increase in the $\mathrm{Fe}^{3+}$ concentration indicates cation-induced aggregation of AuNPs. The shift in the peak is linear up to 1 equivalent of $\mathrm{Fe}^{3+}$ (Figure 4 inset), indicating the formation of a 1:1 complex with a strong 


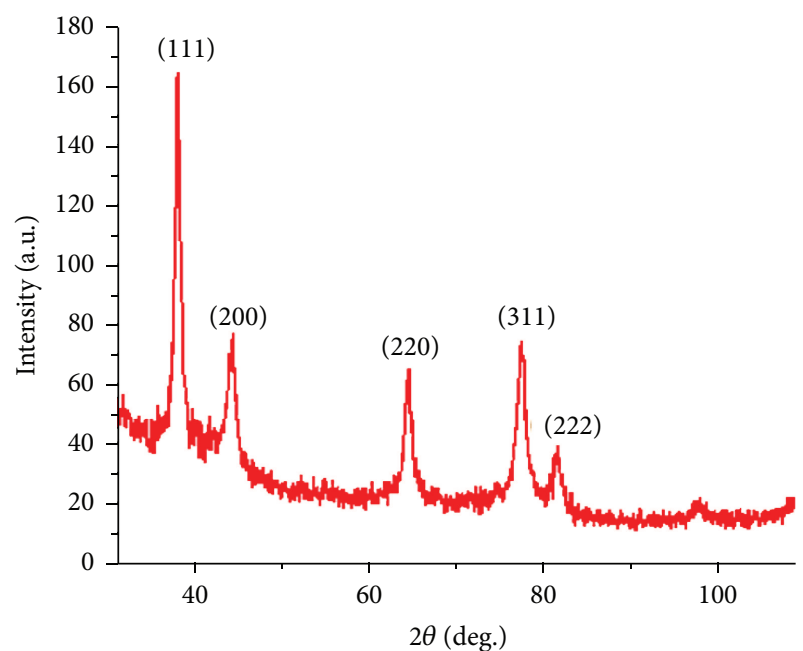

(a)

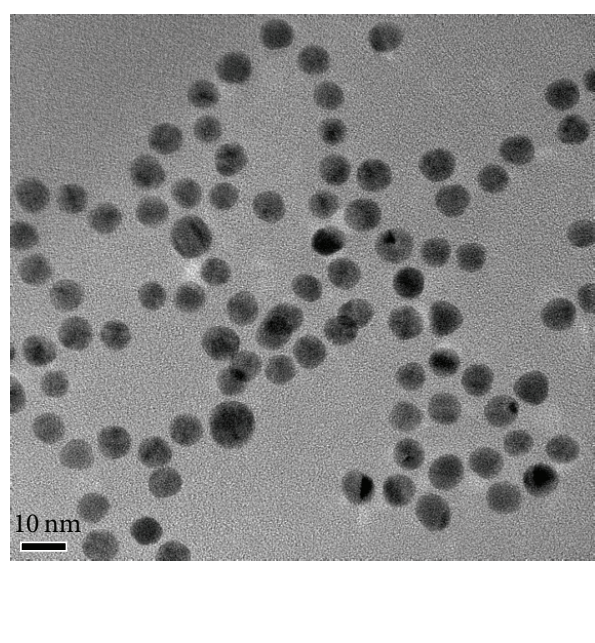

(b)

FIGURE 1: (a) XRD pattern and (b) TEM image of the synthesized AuNP@L.

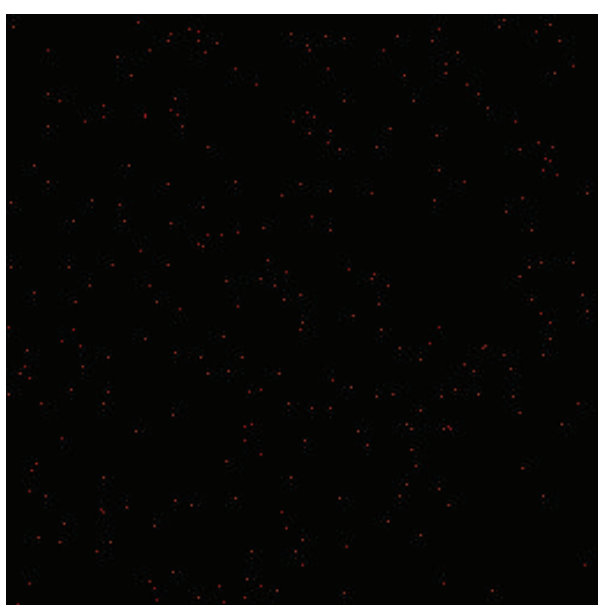

(a)

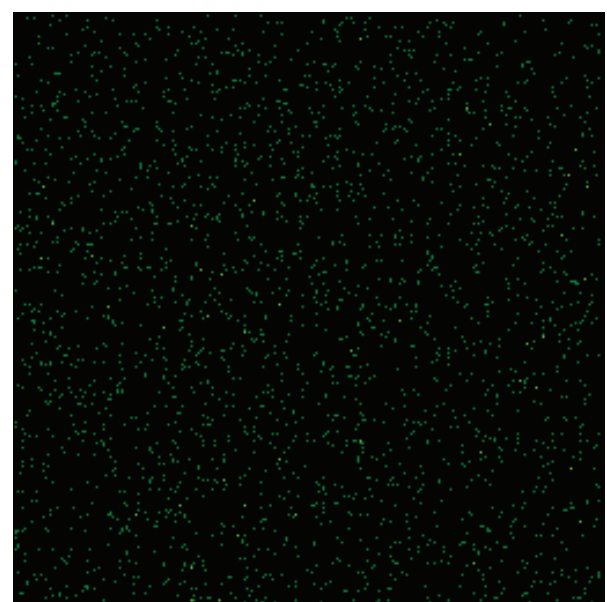

(b)

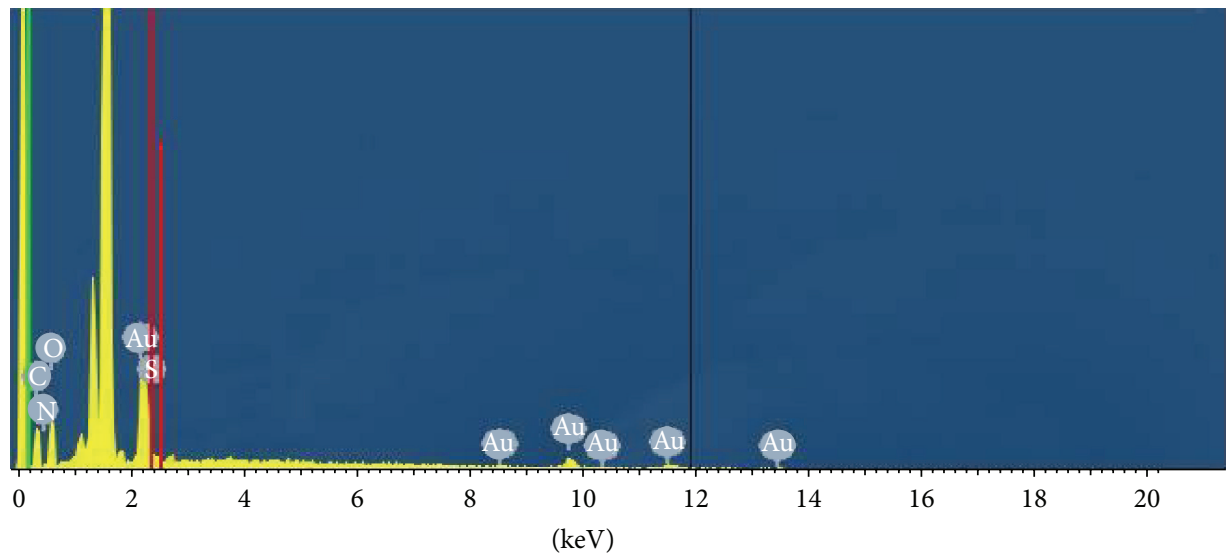

(c)

Figure 2: Elemental mapping images of AuNP@L showing (a) gold and (b) sulfur; (c) EDX spectrum of AuNP@L. 


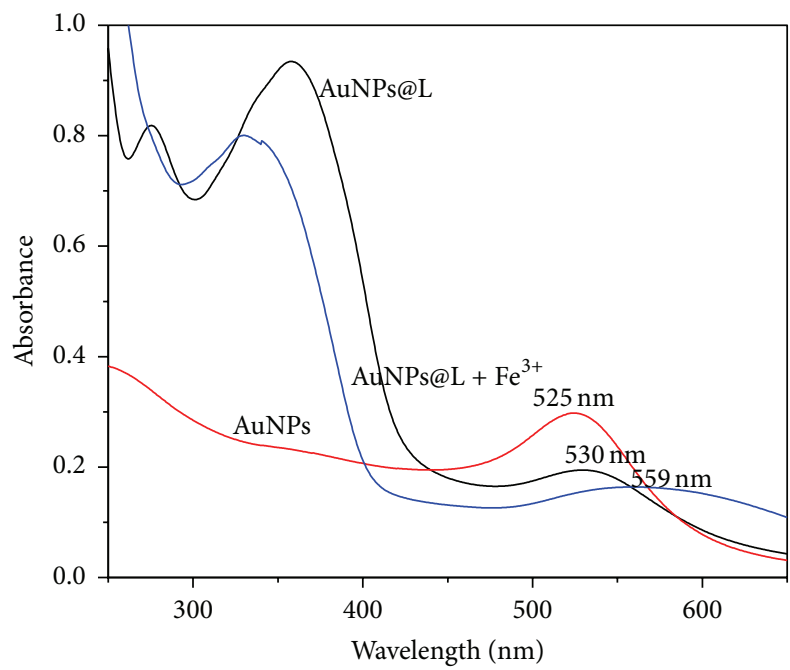

FIGURE 3: UV-Vis absorption spectra of AuNP@Cit, AuNP@L, and $\mathrm{AuNP} @ \mathrm{~L}+\mathrm{Fe}^{3+}$.

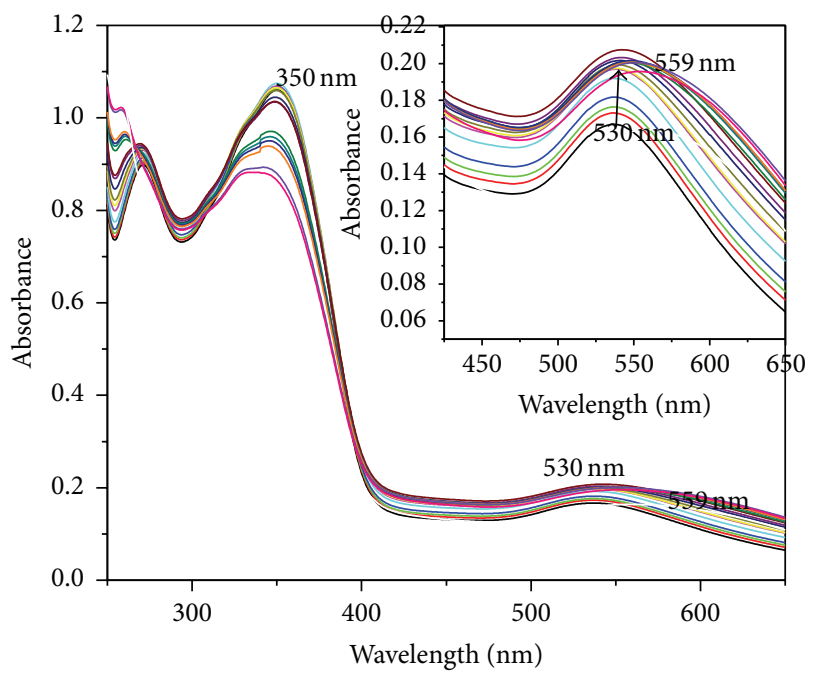

FIgURE 4: Evolution of the UV-Vis spectra of AuNP@L (10 $\mu \mathrm{M})$ upon the addition of $\mathrm{Fe}\left(\mathrm{NO}_{3}\right)_{3}$ in a $(9: 1) \mathrm{EtOH}: \mathrm{H}_{2} \mathrm{O}$ mixture. Inset: exploded view of the shift of the plasmonic absorption peak from 530 to $559 \mathrm{~nm}$ with increasing ferric ion concentration.

affinity (binding constant: $8.5 \times 10^{5} \mathrm{M}^{-1}$; estimated error $\leq$ 10\%) [38].

3.3. Photoluminescence Studies. The results of the photoluminescence studies of AuNP@L with iron (concentration: $10 \mu \mathrm{M})$ in $10 \%(\mathrm{v} / \mathrm{v})$ water/ethanol are shown in Figure 5. The emission peak at $491 \mathrm{~nm}$ upon excitation with $390 \mathrm{~nm}$ radiation resulted from the intramolecular charge transfer (ICT) between the imine groups and the phenolic groups of the ligands in AuNP@L.The addition of ferric ions quenched the fluorescent emission due to chelation-enhanced quenching (CEQ) because $\mathrm{Fe}^{3+}$ is paramagnetic. The quenching in the presence of iron provides a very fast and efficient nonradiative

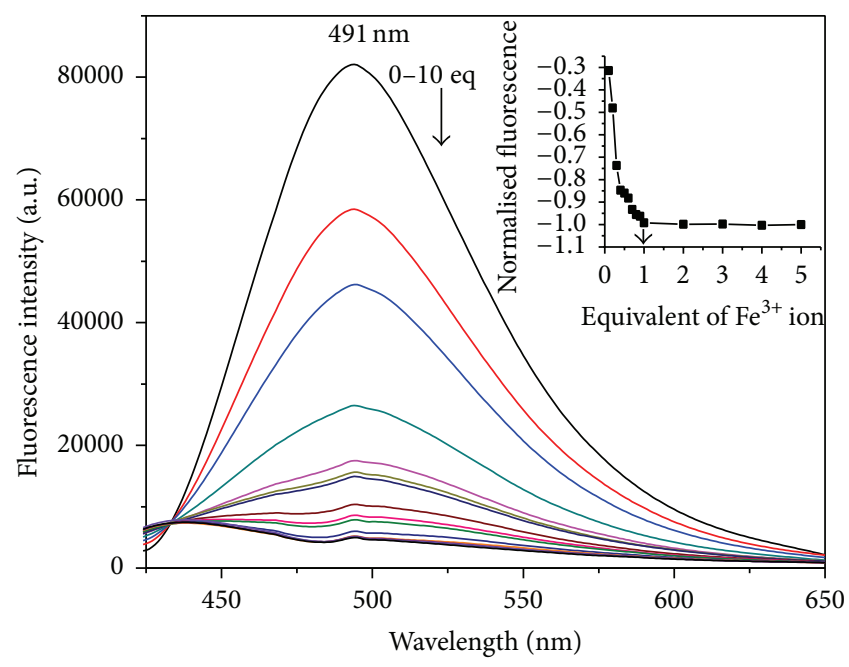

FIGURE 5: Fluorescence titration of AuNP@L $(10 \mu \mathrm{M}) \mathrm{H}_{2} \mathrm{O}: \mathrm{EtOH}$ (1:9) $\left(\lambda_{\mathrm{ex}}=390 \mathrm{~nm}\right)$. Inset: mole ratio plot of the emission at $491 \mathrm{~nm}$.

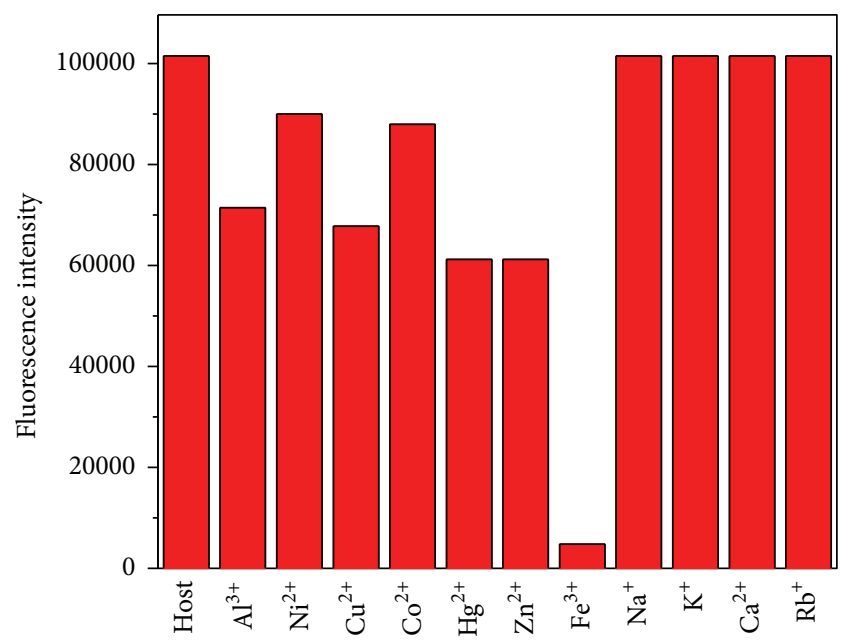

FIgURE 6: Metal-ion selectivity of AuNP@L; bars indicate the fluorescence intensity (excitation at $390 \mathrm{~nm}$ and emission at $491 \mathrm{~nm}$ ). Nitrate salts of various metal ions (10.0 equivalents) were added to AuNP@L $(10 \mu \mathrm{M})$ in $\mathrm{H}_{2} \mathrm{O}: \mathrm{EtOH}(1: 9)$.

decay of the excited states due to the electron or energy transfer between the cations and the ligands.

3.4. Competition with Other Metal Ions. The selectivity and tolerance of AuNP@L for $\mathrm{Fe}^{3+}$ over other cations were investigated by adding 10 equivalents of various metal ions to $10 \mu \mathrm{M}$ of AuNP@L (Figure 6). Partial quenching occurred with $\mathrm{Al}^{3+}$, $\mathrm{Cu}^{2+}, \mathrm{Hg}^{2+}$, and $\mathrm{Zn}^{2+}$, as shown in Figure 5, whereas the molecular fluorescence was quenched to a maximum level with $\mathrm{Fe}^{3+}$, indicating that AuNP@L exhibited the highest sensitivity for ferric ion detection.

This observation was attributed to the difference in the coordinative interaction energy for various cations that otherwise do not substantially differ in ionic size. Thus, this energy difference can be exploited for discriminative 
TABLE 1: Comparison of the detection limit AuNPs@L with similar system.

\begin{tabular}{lccc}
\hline System & $\begin{array}{c}\text { Detection } \\
\text { limit }\end{array}$ & Medium & References \\
\hline Carbon Dots (CD) & $2.0 \times 10^{-9} \mathrm{M}$ & Ionic liquid & {$[40]$} \\
AuNP-thiourea & $8.9 \times 10^{-4} \mathrm{M}$ & Aqueous & {$[41]$} \\
MOFs & $1.0 \times 10^{-7} \mathrm{M}$ & DMF & {$[42]$} \\
AuNP@L & $12 \times 10^{-7} \mathrm{M}$ & Ethanol:water & Present work \\
& & $(9: 1)$ & \\
\hline
\end{tabular}

purposes, especially for fluorescent sensing [39]. $\mathrm{Fe}^{3+}$ exhibits high thermodynamic affinity for phenolic- $\mathrm{C}=\mathrm{N}$ and $-\mathrm{OH}$ groups, which is a hybrid of the imino nitrogen of the amine and the oxygen of the phenol ring; this hybrid is formed as a result of the strong tendency of phenol to undergo deprotonation during complex formation, with fast metal-toligand binding kinetics that are otherwise not possible with other transition-metal ions. The estimated detection limit of AuNP@L is $1.2 \mu \mathrm{M}$ for $\mathrm{Fe}^{3+}$.

Although the fluorescence turn on approach is more effective than switch off approach, the probe, AuNP@L, was selective to $\mathrm{Fe}^{3+}$ compared to the other biologically relevant metal ions $\left(\mathrm{Cu}^{2+}, \mathrm{Zn}^{2+}\right.$, etc.). It also has a comparable detection limit of $1.2 \mu \mathrm{M}$ for $\mathrm{Fe}^{3+}$. Moreover the absorption and emission spectral studies showed a 1:1 binding mode for $\mathrm{Fe}^{3+}$, with strong binding constants of $8.5 \times 10^{5}$ and $2.9 \times 10^{5} \mathrm{M}^{-1}$, respectively. The obtained detection limit is comparable with the literature data for the detection of the $\mathrm{Fe}^{3+}$ in different system (Table 1).

\section{Conclusion}

In summary, we have prepared a simple and sensitive nanogold-based Schiff base chemosensor that exhibits high selectivity toward ferric ions compared to other cations in a water/ethanol mixture. The AuNP@L was characterized by UV-visible absorption spectroscopy, photoluminescence, TGA, and TEM. The detection limit for $\mathrm{Fe}^{3+}$ ions was estimated to be $1.2 \mu \mathrm{M}$, without interference from other metal ions. The binding mode was $1: 1$ and the binding constants were $8.5 \times 10^{5} \mathrm{M}^{-1}$ and $2.9 \times 10^{5} \mathrm{M}^{-1}$, as calculated from the results of absorption and emission titrations, respectively. Thus from sensing point of view this probe can be used in the physiological system with good selectivity and sensitivity for the detection of $\mathrm{Fe}^{3+}$.

\section{Conflict of Interests}

The authors declare that there is no conflict of interests regarding the publication of this paper.

\section{Acknowledgments}

This project was funded by the National Plan for Science, Technology and Innovation (MAARIFAH), King Abdulaziz City for Science and Technology, through the Science and
Technology Unit at King Fahd University of Petroleum and Minerals (KFUPM), the Kingdom of Saudi Arabia, Award no. 12-NAN2389-04. The authors also gratefully acknowledge the Center of Research Excellence in Nanotechnology (CENT) for providing all facilities for analysis.

\section{References}

[1] S. Ruan, X. Cao, X. Cun et al., "Matrix metalloproteinasesensitive size-shrinkable nanoparticles for deep tumor penetration and $\mathrm{pH}$ triggered doxorubicin release," Biomaterials, vol. 60, pp. 100-110, 2015.

[2] O. Penon, T. Patiño, L. Barrios et al., "A new porphyrin for the preparation of functionalized water-soluble gold nanoparticles with low intrinsic toxicity," ChemistryOpen, vol. 4, no. 2, pp. 127136, 2015.

[3] P.-J. Debouttière, S. Roux, F. Vocanson et al., "Design of gold nanoparticles for magnetic resonance imaging," Advanced Functional Materials, vol. 16, no. 18, pp. 2330-2339, 2006.

[4] M. N. Shaikh, H.-K. Kim, J.-A. Park, Y. Chang, and T.-J. Kim, "Gold nanoparticles coated with Gd-chelate as a potential CT/MRI bimodal contrast agent," Bulletin of the Korean Chemical Society, vol. 31, no. 5, pp. 1177-1181, 2010.

[5] C. Qian, W. Han, L. Hui et al., "Multifunctional dendrimerentrapped gold nanoparticles modified with RGD peptide for targeted computed tomography/magnetic resonance dualmodal imaging of tumors," Analytical Chemistry, vol. 87, no. 7, pp. 3949-3956, 2015.

[6] S. Wu, S. Yan, W. Qi et al., "Green synthesis of gold nanoparticles using aspartame and their catalytic activity for $p$-nitrophenol reduction," Nanoscale Research Letters, vol. 10, no. 1, pp. 1-7, 2015.

[7] C. Peng, X. Duan, Z. Xie, and C. Liu, "Shape-controlled generation of gold nanoparticles assisted by dual-molecules: the development of hydrogen peroxide and oxidase-based biosensors," Journal of Nanomaterials, vol. 2014, Article ID 576082, 7 pages, 2014.

[8] A. M. Mohammed, R. A. Rahim, I. J. Ibraheem et al., "Application of gold nanoparticles for electrochemical DNA biosensor," Journal of Nanomaterials, vol. 2014, Article ID 683460, 7 pages, 2014.

[9] M.-C. Daniel and D. Astruc, "Gold nanoparticles: assembly, supramolecular chemistry, quantum-size-related properties, and applications toward biology, catalysis, and nanotechnology," Chemical Reviews, vol. 104, no. 1, pp. 293-346, 2004.

[10] C. Burda, X. Chen, R. Narayanan, and M. A. El-Sayed, "Chemistry and properties of nanocrystals of different shapes," Chemical Reviews, vol. 105, no. 4, pp. 1025-1102, 2005.

[11] J. J. Du, L. Jiang, Q. Shao et al., "Colorimetric detection of mercury ions based on plasmonic nanoparticles," Small, vol. 9, no. 9-10, pp. 1467-1481, 2013.

[12] P. Galletto, P. F. Brevet, H. H. Girault, R. Antoine, and M. Broyer, "Enhancement of the second harmonic response by adsorbates on gold colloids. The effect of aggregation," The Journal of Physical Chemistry B, vol. 103, no. 41, pp. 8706-8710, 1999.

[13] B. D'Autréaux, N. P. Tucker, R. Dixon, and S. Spiro, "A non-haem iron centre in the transcription factor NorR senses nitric oxide," Nature, vol. 437, no. 7059, pp. 769-772, 2005.

[14] Y. Xing and A. Ton, "A new rhodamine-based chemosensor exhibiting selective $\mathrm{Fe}^{I I I}$-amplified fluorescence," Organic Letters, vol. 8, no. 8, pp. 1549-1552, 2006. 
[15] G. E. Tumambac, C. M. Rosencrance, and C. Wolf, "Selective metal ion recognition using a fluorescent 1,8diquinolylnaphthalene-derived sensor in aqueous solution," Tetrahedron, vol. 60, no. 49, pp. 11293-11297, 2004.

[16] N. Narayanaswamy and T. Govindaraju, "Aldazine-based colorimetric sensors for $\mathrm{Cu}^{2+}$ and $\mathrm{Fe}^{3+}$, Sensors and Actuators $\mathrm{B}$ : Chemical, vol. 161, no. 1, pp. 304-310, 2012.

[17] J.-W. Lee and J. D. Helmann, "The PerR transcription factor senses $\mathrm{H}_{2} \mathrm{O}_{2}$ by metal-catalysed histidine oxidation," Nature, vol. 440, no. 7082, pp. 363-367, 2006.

[18] E. D. Weinberg, "The role of iron in cancer," European Journal of Cancer Prevention, vol. 5, no. 1, pp. 19-36, 1996.

[19] Z. Li, Y. Zhou, K. Yin, Z. Yu, Y. Li, and J. Ren, "A new fluorescence 'turn-on' type chemosensor for $\mathrm{Fe}^{3+}$ based on naphthalimide and coumarin," Dyes and Pigments, vol. 105, pp. 7-11, 2014.

[20] S. A. Lee, G. R. You, Y. W. Choi et al., "A new multifunctional Schiff base as a fluorescence sensor for $\mathrm{Al}^{3+}$ and a colorimetric sensor for $\mathrm{CN}$ - in aqueous media: an application to bioimaging," Dalton Transactions, vol. 43, no. 18, pp. 6650-6659, 2014.

[21] Y. Zhou, H. N. Kim, and J. Yoon, "A selective 'Off-On' fluorescent sensor for $\mathrm{Zn}^{2+}$ based on hydrazone-pyrene derivative and its application for imaging of intracellular $\mathrm{Zn}^{2+}$, Bioorganic and Medicinal Chemistry Letters, vol. 20, no. 1, pp. 125-128, 2010.

[22] Z. Dong, X. Tian, Y. Chen, Y. Guo, and J. Ma, "Dansyl derivative functionalized $\mathrm{Fe}_{3} \mathrm{O}_{4} @ \mathrm{SiO}_{2}$ fluorescent probe for detection and removal of $\mathrm{Hg}^{2+}$ in aqueous solution," RSC Advances, vol. 3, no. 4, pp. 1082-1088, 2013.

[23] K. Pomazal, C. Prohaska, I. Steffan, G. Reich, and J. F. K. Huber, "Determination of $\mathrm{Cu}, \mathrm{Fe}, \mathrm{Mn}$, and $\mathrm{Zn}$ in blood fractions by SEC-HPLC-ICP-AES coupling," Analyst, vol. 124, no. 5, pp. 657663, 1999.

[24] M. E. Del Castillo Busto, M. Montes-Bayón, E. BlancoGonzález, J. Meija, and A. Sanz-Medel, "Strategies to study human serum transferrin isoforms using integrated liquid chromatography ICPMS, MALDI-TOF, and ESI-Q-TOF detection: application to chronic alcohol abuse," Analytical Chemistry, vol. 77, no. 17, pp. 5615-5621, 2005.

[25] G. L. Arnold, S. Weyer, and A. D. Anbar, "Fe isotope variations in natural materials measured using high mass resolution multiple collector ICPMS," Analytical Chemistry, vol. 76, no. 2, pp. 322-327, 2004.

[26] J. E. T. Andersen, "A novel method for the filterless preconcentration of iron," Analyst, vol. 130, no. 3, pp. 385-390, 2005.

[27] M. G. Constant and D. Van Berg, "Chemical speciation of iron in seawater by cathodic stripping voltammetry with dihydroxynaphthalene," Analytical Chemistry, vol. 78, no. 1, pp. 156-163, 2006.

[28] O. Tour, S. R. Adams, R. A. Kerr et al., "Calcium Green FlAsH as a genetically targeted small-molecule calcium indicator," Nature Chemical Biology, vol. 3, no. 7, pp. 423-431, 2007.

[29] J. L. Bricks, A. Kovalchuk, C. Trieflinger et al., "On the development of sensor molecules that display $\mathrm{Fe}^{3+}$ - amplified fluorescence," Journal of the American Chemical Society, vol. 127, no. 39, pp. 13522-13529, 2005.

[30] M. Y. She, Z. Yang, B. Yin et al., "A novel rhodamine-based fluorescent and colorimetric 'off-on' chemosensor and investigation of the recognizing behavior towards $\mathrm{Fe}^{3+}$, Dyes and Pigments, vol. 92, no. 3, pp. 1337-1343, 2012.

[31] M. X. Zhang, G. Y. Qing, C. L. Xiong, R. Cui, D.-W. Pang, and T. L. Sun, "Dual-responsive gold nanoparticles for colorimetric recognition and testing of carbohydrates with a dispersiondominated chromogenic process," Advanced Materials, vol. 25, no. 5, pp. 749-754, 2013.

[32] L. Bai, L. Zhu, C. Y. Ang et al., "Iron(III)-quantity-dependent aggregation-dispersion conversion of functionalized gold nanoparticles," Chemistry, vol. 20, no. 14, pp. 4032-4037, 2014.

[33] F. Tisato, F. Refosco, U. Mazzi, G. Bandoli, and M. Nicolini, "Technetium $(\mathrm{V})$ and rhenium $(\mathrm{V})$ complexes with $\mathrm{N}-(2$ mercaptophenyl)salicylideneiminate. Crystal structure of chloro(oxo)[N-(2-sulphidophenyl)salicylideneiminatoNOS] technetium(V)," Journal of the Chemical Society, Dalton Transactions, no. 7, pp. 1693-1699, 1987.

[34] K. C. Grabar, R. Griffith Freeman, M. B. Hommer, and M. J. Natan, "Preparation and characterization of Au colloid monolayers," Analytical Chemistry, vol. 67, no. 4, pp. 735-743, 1995.

[35] J.-A. Park, P. A. N. Reddy, H.-K. Kim et al., "Gold nanoparticles functionalised by Gd-complex of DTPA-bis(amide) conjugate of glutathione as an MRI contrast agent," Bioorganic \& Medicinal Chemistry Letters, vol. 18, no. 23, pp. 6135-6137, 2008.

[36] Joint Committeeof Powder Diffraction Standard (JCPDS) Card No. 04-0784, 2002.

[37] J. Keck, H. E. A. Kramer, H. Port, T. Hirsch, P. Fischer, and G. Rytz, "Investigations on polymeric and monomeric intramolecularly hydrogen-bridged UV absorbers of the benzotriazole and triazine class," Journal of Physical Chemistry, vol. 100, no. 34, pp. 14468-14475, 1996.

[38] K. A. Connors, Binding Constants: The Measurement of Molecular Complex Stability, Wiley, New York, NY, USA, 1987.

[39] L. Fabbrizzi, M. Licchelli, P. Pallavicini, L. Parodi, and A. Taglietti, "Fluorescent sensors for and with transition metals," in Transition Metals in Supramolecuar Chemistry, John Wiley \& Sons, 1999.

[40] R. Liu, M. Gao, J. Zhang et al., "An ionic liquid promoted microwave-hydrothermal route towards highly photoluminescent carbon dots for sensitive and selective detection of iron(III)," RSC Advances, vol. 5, pp. 24205-24209, 2015.

[41] S. J. Tripathy, J. Y. Woo, and C.-S. Han, "Colorimetric detection of Fe(III) ions using label-free gold nanoparticles and acidic thiourea mixture," Sensors and Actuators B, vol. 181, pp. 114-118, 2013.

[42] X.-H. Zhou, L. Li, H.-H. Li, A. Li, T. Yang, and W. Huang, "A flexible $\mathrm{Eu}(\mathrm{III})$-based metal-organic framework: turn-off luminescent sensor for the detection of $\mathrm{Fe}(\mathrm{III})$ and picric acid," Dalton Transactions, vol. 42, no. 34, pp. 12403-12409, 2013. 

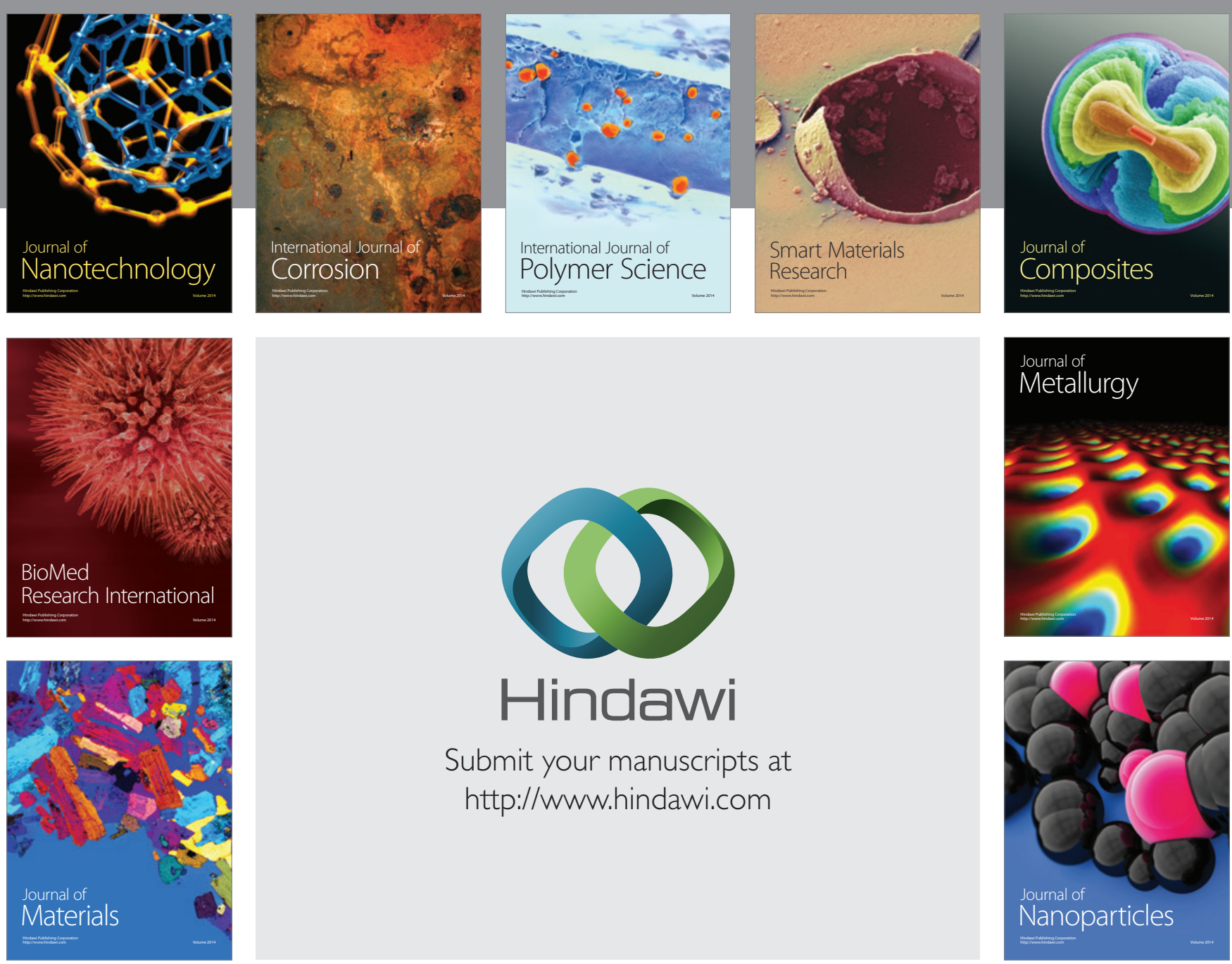

Submit your manuscripts at http://www.hindawi.com
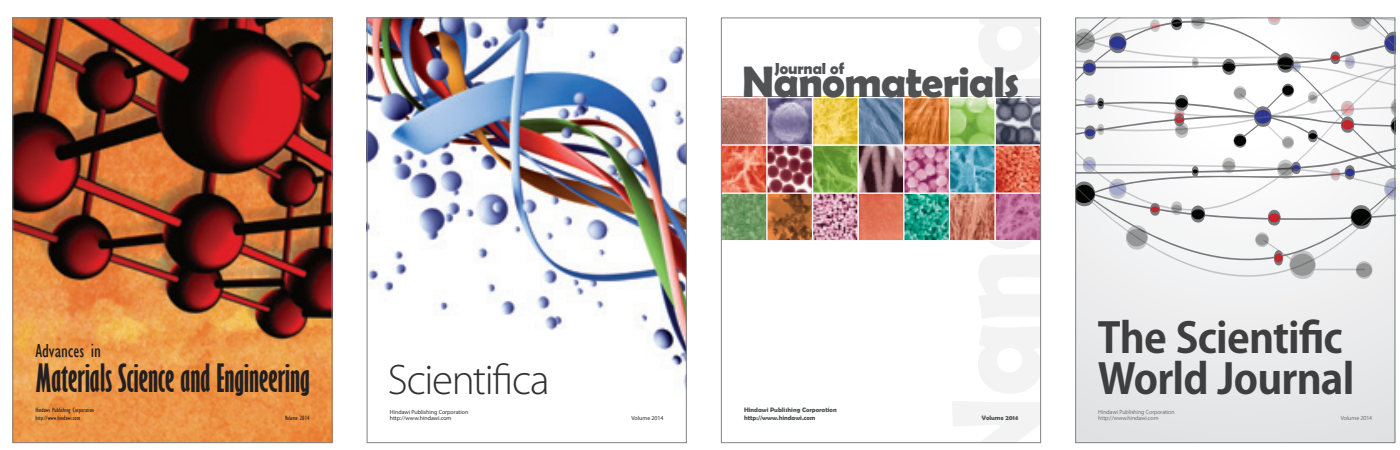

\section{The Scientific World Journal}
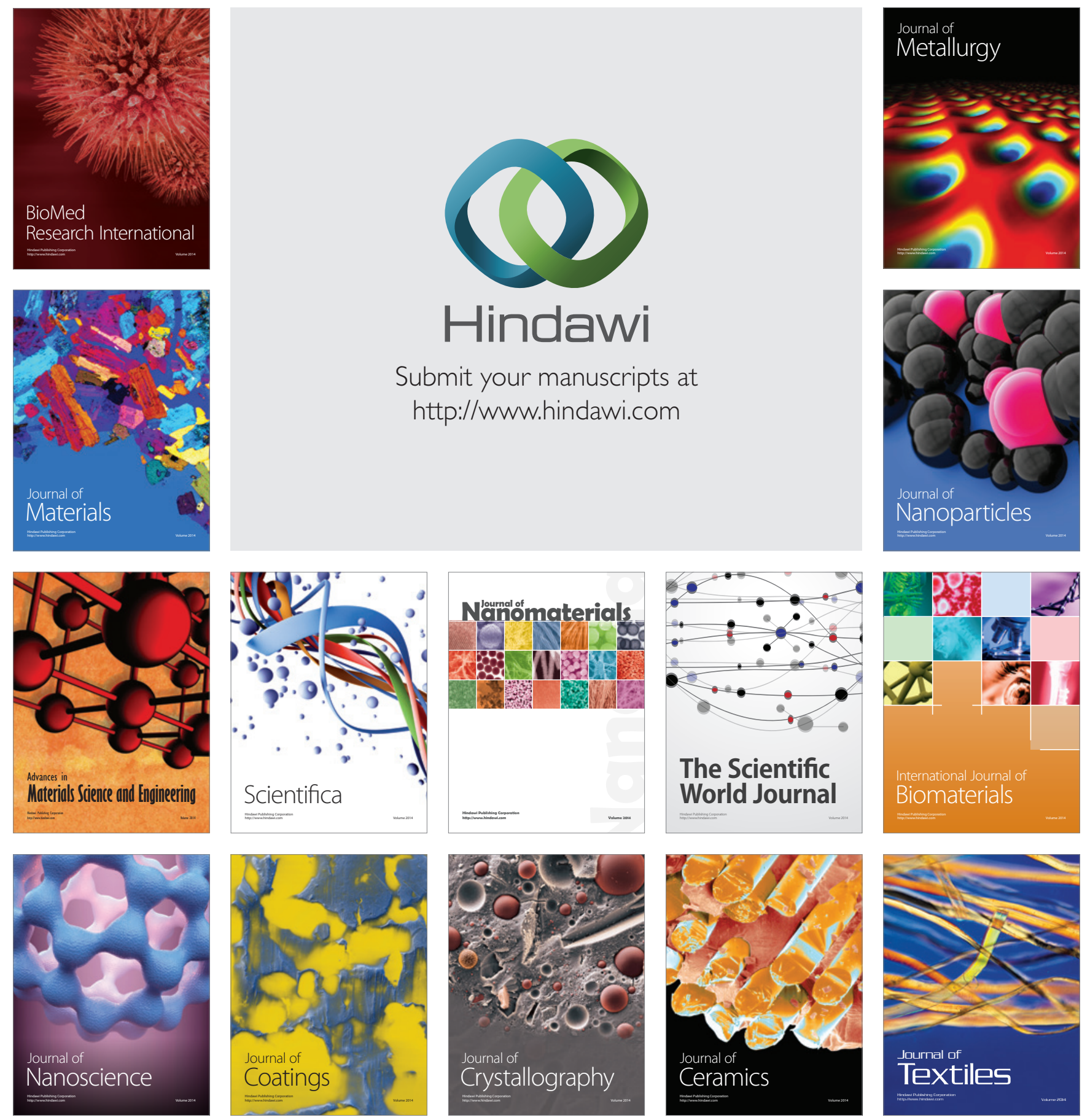